\section{Unparalleled textbook of plant anatomy}

Anatomy of Seed Plants. Second edition. Pp. 550. By Katherine Esau. (Wiley: London and New York, 1977.) $\$ 21.25 ; £ 11.50$.

TWENTY FOUR YeARS AGO, Professor Katherine Esau published her first book, Plant Anatomy. This book rapidly established itself as a standard by which all others have subsequently been judged. As Professor Esau herself points out, however, there was also a need for a shorter book for students who have relatively limited experience in the study of plants. For that reason Anatomy of Seed Plants was first published in 1960 and is now seen in its second edition.

Anatomy of Seed Plants still has to be viewed against the broader, and deeper, backcloth set by Plant Anatomy itself, but it remains an attractive, informative and authoritative book in its own right, even if its price will restrict ownership more severely than one might hope. An important feature of this second edition is that it incorporates very significant changes and is very much more than a new edition in name alone.

An immediately apparent change is in the page format which is now enlarged to $23.3 \mathrm{~cm} \times 18.9 \mathrm{~cm}$ from the previous $22.8 \mathrm{~cm} \times 14.9 \mathrm{~cm}-\mathrm{a}$ $30 \%$ increasc in area. This, together with the fact that the book is extended from 376 to 550 pages, has allowed incorporation of much new material, although the larger page size has often been wasted where micrographs and diagrams from the first edition have been reproduced at the same size. The pleasant format, together with twocolumn presentation, a clearly legible type-face and a balanced distribution of text and illustrations, has led to the production of a book that demands to be read.

Having attracted the reader's attention, what is to be found inside? A major, and immediately obvious feature is the inclusion of numerous electron micrographs. There were only a couple in the first edition, but the present book is liberally laced with them and they are, as are most of the other illustrations chosen, of good quality. If anything, the half-tones in the present volume are of better contrast than those in the original.

Professor Esau's attention to detail is prodigious and only the closest scrutiny of the book reveals many of the smaller changes that have been made to take account of advances in knowledge or interpretation over the past 16 years. (The abbreviation for micrometre is now given in its proper form $(\mu \mathrm{m})$ but it is a pity that the Angström lingers on.) The enormous task of encompassing new information without completely losing sight of the old has largely been achieved by combining subject matter as much as possible, and by referring only to key items of interest within a particular arca of study. Similarly, the references, though strictly limited, serve to acquaint the reader with the most recent work and generally include at least one paper Irom each main laboratory contributing to a specific field of interest. In this way, Anatomy of Seed Plants is able to cover a large subject area while allowing the reader

\section{Diatom biology}

Biology of Diatoms. Edited by Dietrich Werner. Pp. 498. (Blackwell Scientific: Oxford, 1977.) $£ 17$.

FEw algal groups have seen such an expansion of interest over the past two decades as the diatoms, and this volume admirably covers the recent developments. It may come as a surprise to many to read on the first page that it is estimated that diatoms contribute $20-25 \%$ of the world's net primary production-a figure derived from experimental studics which almost certainly underestimate true production. Such production at the base of so many food chains ought to stimulate work on grazing, yet this is hardly begun and is mentioned on only a few pages.

Although the title might imply that this book can be read to obtain an overall survey of the diatoms, this is not so, and a student with little knowledge of the group would find it difficult. There is no section on morphology, no simple explanation of cell division, few illustrations of the major groups; and those given are of centric genera leaving a student to guess at pennate morphology.

Growth, nutrition, chemical composition, movement, sexuality, ecology are all discussed; in these chapters, each written by a different author, there is a wealth of data and excellent references. The authors of the chapter on the ecology of marine planktonic diatoms have assembled a mass of fascinating data on distribution in the seas of the world which is a valuable contribution to the much neglected topic of biogeography.

In many places, however, the text is clearly written in review form and the opportunity to find his way more deeply into plant anatomy if he so desires.

Anatomy of Seed Plants is unashamedly a textbook of anatomy. As such it is unparallelled. Although the modern trend is, and must be, to combine structure and function in our approach to the way plants work, this can only be accomplished if our basic knowledge of plant anatomy is both broad and sound. Professor Esau has ensured that no botanist-whether student or research worker-will have the excuse that the right information is not readily, and attractively, to hand.

A. W. Robards

A. W. Robards is Senior Lecturer in the Department of Biology at the University of York, UK.

many statements merely stimulate and necessitate consultation of the original papers. The chapter on sexuality will be of great value to many students since much of the excellent original work is very discursive and written in German.

A chapter on ultrastructure reviews the literature but is very poorly illustrated with three very indistinct pictures, all of Cylindrotheca which has an unusual morphology. This is a pity since there are now several excellent studies of diatom ultrastructure. Also, apart from a few photographs of ccntric diatoms, the considerable body of information on the ultrastructure of the siliceous components has not been utilised. The old concept of diatoms as a class of the Chrysophyta again crops up in some chapters although they were clearly recognised as a division, Bacillariophyta, in the system of Hustedt (1930) and are so distinctive that there can be surely little argument about this in 1977.

Biochemical and physiological studies have blossomed in the past two decades, and the information in the chapters on growth, silicate metabolism, photosynthesis, heterotrophic nutrition and biochemical composition will surprise many who have not followed the field closely. The chapter on silicate metabolism is of great value, since it is a synthesis of chemical and biological studies and provides a valuable introduction to the complexities of silicon chemistry.

The combination of authors has resulted in some repetition of data in several chapters but not in any serious way. The book is well produced, relatively free of errors and will be a source of considerable value for many years to come.

F. E. Round

F. E. Round is Reader in Phycology at the University of Bristol, UK. 